\title{
Organizational approaches to implement rapid change in hospitals to respond to public health emergencies
}

The COVID-19 pandemic has intensified the need for crisis preparedness among public health systems worldwide. Securing both human and financial resources to improve standards of health care remains a global priority (1-4). Yet, efforts to improve preparedness lack the necessary frameworks to develop and sustain improvements in health care systems' processes and outcomes $(5,6)$. The sudden and far-reaching impact of the COVID-19 pandemic has prompted scientists to develop frameworks that aim to adequately prepare hospitals and other health service delivery systems for surges in demand for care. A report on the operational readiness of nations on several indicators of preparedness found that only $57 \%$ of 182 countries had the functional capacity to execute crucial emergency-related activities (7). Elements of health care systems that have been implicated in low levels of preparedness have varied, ranging from supply chain failures, workforce shortages, organizational readiness for change, and resource constraints, among others $(8,9)$. The COVID-19 pandemic has certainly impacted these elements. With decades of organizational research on the adoption and implementation of innovative practices, system and organizational scientists are poised to help health care organizations respond to the need for technical, financial, and cultural resources to effectively address public health crises (10-12). In this special issue, we embarked on an exploration of health care systems' capacity to respond to increasing public health challenges, to meet the global imperative for more efficient and effective crisis preparedness infrastructure.

This special issue on "organizational approaches to implement rapid change in hospitals to respond to public health emergencies" presents conceptual and empirical papers on various approaches that hospitals and other health care organizations could implement to counteract current (e.g., the COVID-19 pandemic), ongoing (e.g., HIV, opioid overdose) and emerging epidemics that will impact global health. The purpose of this special issue is to advance Systems, as well as Organizations and Implementation Sciences by developing and testing frameworks that lead to a highly responsive and effective public health system. These interdisciplinary sciences focus on simple to complex systems, and implementation methods that lead to the integration of evidence-based practices. These interventions and resulting policies must necessarily be translated into routine practice in health care organizations.

The papers included in this series use different levels of analysis (i.e., individual, group, organization or system) and are informed by different disciplinary frameworks. Despite these differences, all of these papers share a focus on implementing innovation and improving readiness among hospitals and allied health providers to effectively respond to public health emergencies. There are four papers in this series that represent some of the core functions and challenges of hospital response to COVID-19.

The first paper in the series explores how the concept of organizational slack applies to hospital system responsiveness during the COVID-19 pandemic. Drs. McHugh and Cross (13) focus on hospitals that had higher capacity to effectively respond to the pandemic. Relying on the organizational slack literature, the authors describe a conceptual model based on using social capital and financial health to effectively respond to COVID-19. Innovation and operational flexibility are proposed as key areas that afford healthcare organizations the ability to adapt in response to imminent change (McHugh and Cross, 2021).

To effectively respond to COVID-19, hospitals need to have strong teams with effective crisis management practices. Drs. Porter, Rathert, Ayad, and Messina are the authors of the second paper. In this paper, the authors use the One-Team approach to crisis management in an hospital setting and highlight the success story during the COVID-19 pandemic (14). They report that financial decline precipitated by COVID-19 pressured hospitals to both shrink their workforce and at the same time strengthen their teams at different levels to respond to the public health crisis. Drawing from social identity theory, the authors focus on the importance of conceptualizing and operationalizing organizational level team. They offer an organizational exemplar, the Cleveland Clinic, which used teams effectively to reduce negative organizational consequences to their workforce and regular practices.

In the third paper of the series, Drs. Muskopf, Sudan, Verdooner, and Nair advance understanding of the role of 
organizational learning in hospitals' response to crisis management with regard to COVID-19 (15). Focusing on the practice of disaster management and crisis-driven changes, the authors review published case studies that reveal which components of change were most effective in preparing hospitals to respond to patients care challenges during the COVID-19 pandemic. The authors focus on efforts to help professionals and policy makers developed robust responses across different countries in the world. Their findings inform a framework for optimal patient care response, including the use of big data systems.

The last paper in the series is written by Drs. Choflet, Packard, and Stashower, who also offer a framework on organizational change that can be used to design organizations with the ability to effectively adapt to different types of change (16). In their article, which focuses on organizational change and the need to rethink existing approaches, especially in Covid-19 era, the authors advance a planned organizational change framework relying on complexity theory. The theory informs their conceptualization of hospitals as complex adaptive systems, and how this framing can better position organizations to respond to COVID-19 and future emergent public health challenges. The authors redesign areas such as constant assessment, ongoing high levels of communication, iterative cycles of experimentation, reflection and learning, and use of leadership behaviors in order to improve decision-making. The paper highlights key practices that can be used to adapt the organizational change needs of healthcare organizations.

These four articles provide conceptual frameworks and empirical data that inform best practices for healthcare organizations, and effectively responding to the multiple challenges resulting from the COVID-19 pandemic. Preparing hospitals and other health care delivery organizations to respond to crises more effectively, both current and emerging, will requires additional understanding of the complex relationship between patients' needs and demands, and resources at multiple levels. This special issue addresses a broad range of topics important to enhancing organizational approaches that promote the rapid and effective implementation of change in health care systems in response to public health emergencies. It centers Innovation and operational flexibility, effective crisis management practices, organizational learning and translation of big data systems, and rethinking organizational change, within the framework of complex adaptive systems, as relevant factors in organizational preparedness to manage crises. It also contributes to the growing knowledge on health care organizations and individuals within them as critical actors in addressing public health crises. We are enthusiastic about the possibilities that the findings of these studies present for practice and policy. We are also eager to see how future research furthers the studies were included in this issue and provides new insight into effective preparation and sustainability of efforts in response to public health emergencies.

\section{Acknowledgments}

We would like to acknowledge the research team at I-LEAD Institute, particularly Ms. Veronica Serret for the coordination of the material reviewed, and Ms. Mona Zahir, for typesetting the narrative of this article.

Funding: We also acknowledge funding from Research to End Healthcare Disparities Corp to support the editorial support of this special issue.

\section{Footnote}

Provenance and Peer Review: This article was commissioned by the editorial office for the series "Organizational Approaches to Implement Rapid Change in Hospitals to Respond to Public Health Emergencies" published in Fournal of Hospital Management and Health Policy. The article did not undergo external peer review.

Conflicts of Interest: Both authors have completed the ICMJE uniform disclosure form (available at https://dx.doi. org/10.21037/jhmhp-2021-05). The series "Organizational Approaches to Implement Rapid Change in Hospitals to Respond to Public Health Emergencies” was commissioned by the editorial office without any funding or sponsorship. EG served as an unpaid Guest Editor of the series and serves as an unpaid editorial board member of fournal of Hospital Management and Health Policy from Oct 2019 to Sept 2021. Dr. Guerrero reports that I-Lead Institute supported his time spent in this work. JAF served as an unpaid Guest Editor of the series. The authors have no other conflicts of interest to declare. 
Ethical Statement: The authors are accountable for all aspects of the work in ensuring that questions related to the accuracy or integrity of any part of the work are appropriately investigated and resolved.

Open Access Statement: This is an Open Access article distributed in accordance with the Creative Commons AttributionNonCommercial-NoDerivs 4.0 International License (CC BY-NC-ND 4.0), which permits the non-commercial replication and distribution of the article with the strict proviso that no changes or edits are made and the original work is properly cited (including links to both the formal publication through the relevant DOI and the license). See: https://creativecommons.org/licenses/by-nc$\mathrm{nd} / 4.0 /$.

\section{References}

1. Nhan C, Laprise R, Douville-Fradet M, et al. Coordination and resource-related difficulties encountered by Quebec's public health specialists and infectious diseases/medical microbiologists in the management of A (H1N1)--a mixed-method, exploratory survey. BMC Public Health 2012;12:115.

2. Jacobsen KH, Aguirre AA, Bailey CL, et al. Lessons from the Ebola Outbreak: Action Items for Emerging Infectious Disease Preparedness and Response. Ecohealth 2016;13:200-12.

3. Murthy BP, Molinari NM, LeBlanc TT, et al. Progress in Public Health Emergency Preparedness-United States, 2001-2016. Am J Public Health 2017;107:S180-5.

4. Lurie N, Wasserman J, Nelson CD. Public health preparedness: evolution or revolution?. Health Aff (Millwood) 2006;25:935-45.

5. Khan Y, O'Sullivan T, Brown A, et al. Public health emergency preparedness: a framework to promote resilience. BMC Public Health 2018;18:1344.

6. Gibson PJ, Theadore F, Jellison JB. The Common Ground Preparedness Framework: A Comprehensive Description of Public Health Emergency Preparedness. Am J Public Health 2012;102:633-42.

7. Jacobsen KH. Will COVID-19 generate global preparedness? Lancet 2020;395:1013-4.

8. Dai T, Zaman MH, Padula WV, et al. Supply chain failures amid Covid-19 signal a new pillar for global health preparedness. J Clin Nurs 2021;30:e1-3.

9. Haider N, Yavlinsky A, Chang YM, et al. The Global Health Security index and Joint External Evaluation score for health preparedness are not correlated with countries' COVID-19 detection response time and mortality outcome. Epidemiol Infect 2020;148:e210.

10. Fernandes Rodrigues Alves M, Vasconcelos Ribeiro Galina S, Dobelin S. Literature on organizational innovation: past and future. Innovation \& Management Review 2018;15:2-19.

11. Stouten J, Rousseau DM, De Cremer D. Successful Organizational Change: Integrating the Management Practice and Scholarly Literatures. ANNALS 2018;12:752-88.

12. Luke DA, Stamatakis KA. Systems Science Methods in Public Health: Dynamics, Networks, and Agents. Annual Review of Public Health 2012;33:357-76.

13. McHugh JP, Cross DA. The application of organizational slack to hospital system responsiveness during the COVID-19 pandemic. J Hosp Manag Health Policy 2021;5:17.

14. Porter TH, Rathert C, Ayad S, et al. A One-Team approach to crisis management: a hospital success story during the COVID-19 pandemic. J Hosp Manag Health Policy 2021;5:18.

15. Muskopf J, Sudan N, Verdooner E, et al. Organizational learning-COVID-19 experience: innovative global practices for improving patient care in crisis response. J Hosp Manag Health Policy 2021;5:20.

16. Choflet A, Packard T, Stashower K. Rethinking organizational change in the COVID-19 era. J Hosp Manag Health Policy 2021;5:16. 


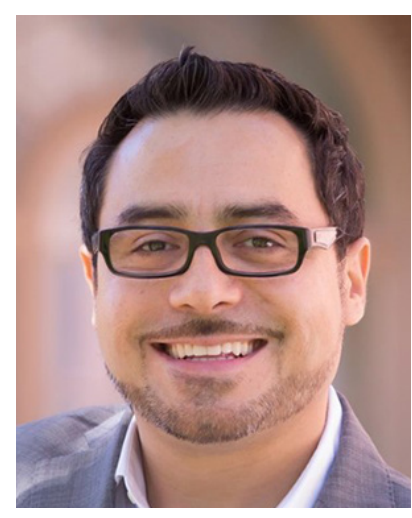

Erick Guerrero

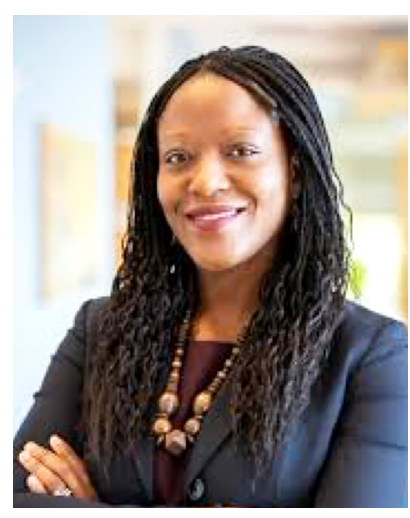

Jemima A. Frimpong

Erick Guerrero, $\mathbf{P h D}$

I-Lead Institute, Research to End Healthcare Disparities Corp, Los Angeles, CA, USA.

(Email: erickguerrer0454@gmail.com) Jemima A. Frimpong, PhD, MPH

Social Science Division, New York University Abu Dhabi, UAE. (Email: jafrimpong@nyu.edu) Received: 20 June 2021; Accepted: 07 July 2021; Published: 25 September 2021. doi: $10.21037 / \mathrm{jhmhp}-2021-05$

View this article at: https://dx.doi.org/10.21037/jhmhp-2021-05

doi: 10.21037/jhmhp-2021-05

Cite this article as: Guerrero E, Frimpong JA. Organizational approaches to implement rapid change in hospitals to respond to public health emergencies. J Hosp Manag Health Policy 2021;5:22. 